\title{
Criminalidad trascendental en la sociedad chilena de Gabriel García Márquez ${ }^{1}$
}

\author{
Jesús Miguel Delgado Del Aguila \\ Candidato a doctor en Literatura Peruana y Latinoamericana \\ Universidad Nacional Mayor de San Marcos, Lima, Perú \\ https://orcid.org/0000-0002-2633-8101 \\ tarmangani2088@outlook.com
}

\section{Resumen}

Los estudios sociológicos permiten en La aventura de Miguel Littín clandestino en Chile (1986) de Gabriel García Márquez revelar una dinámica existente entre dos elementos: el primero, la configuración de la obra literaria sobre la base de referentes históricos que construyen la memoria colectiva y el imaginario de la sociedad chilena; el segundo, el cuestionamiento del concepto de democracia en función de un periodo dictatorial chileno necesario (golpe de Estado de 1973, exilio y violación de los derechos humanos) para el desarrollo trascendental de una nación, apoyada con la Dina, la CNI, las Fuerzas Armadas y otros organismos anticriminales.

Palabras clave: Anticriminal; Chile; democracia; memoria; periodo dictatorial.

\section{Transcendental Criminality in the Chilean Society of Gabriel Garcia Marquez}

\section{Hbstract}

The sociological studies allow in The Adventure of Miguel Littin Clandestine in Chile (1986) of Gabriel Garcia Marquez to reveal a dynamic existing between two elements: the first, the configuration of the literary work on the basis of historical references that build the collective memory and the imaginary of chilean society; the second, the questioning of the concept of democracy in the function of a necessary Chilean dictatorial period (1973 coup, exile and violation of human rights) for the transcendental development of a nation, supported by Dina, $\mathrm{CNI}$, Armed Forces and other anticriminal bodies.

Keywords: Anticriminal; Chile; democracy; memory; dictatorial period.

\footnotetext{
1 Procedencia del artículo: Este artículo surge de intereses individuales. La parte metodológica y teórica se deriva de latesis inédita de maestría Ausencia de un Estado nación en Noticia de un secuestro (1996), a partir de un periodo de macrocriminalidad (dos últimos decenios del siglo XX en Colombia)
} 
Recibido: 16 de septiembre del 2019. Aprobado: 02 de junio del 2020

Artículo de reflexión

https://doi.org/10.25100/poligramas.v0i50.10507

\begin{abstract}
¿Cómo citar este artículo en MLA? - How to quote this article in MLH?
Delgado del Aguila, Jesús. "Criminalidad trascendental en la sociedad chilena de Gabriel García Márquez." Poligramas 50 (2020): n. pag. Web. Fecha de acceso (día, mes en mayúscula y abreviado, y año).
\end{abstract}

En el siguiente artículo de investigación, se pone como referencia la novela de Gabriel García Márquez, La aventura de Miguel Littín clandestino en Chile (1986), que aborda el contexto chileno de la dictadura de Augusto Pinochet (1973-1990). A partir del mismo, vincularé algunos tópicos por desarrollar que son evidentes en la historia de Chile, como también en la novela del Premio Nobel de Literatura de Colombia. Estos temas son la novela histórica como construcción de lo imaginario, el golpe de Estado del 11 de septiembre de 1973, la dictadura y lo delictivo como violación a los derechos humanos, junto con el exilio en Chile. Estos tratados se analizarán esquemáticamente con citas y ejemplos de la novela trabajada, además de emplear postulados de teóricos literarios e historiadores de este país sudamericano. El fin de este trabajo es hallar herramientas teóricas e interpretativas de utilidad para la comprensión de esa imagen simbólica de Chile, insertada históricamente en ese determinado periodo de tiempo en la novela.

\title{
La novela histórica como la construcción de lo imaginario
}

En la primera parte del artículo, analizo la forma en la que la colectividad va construyendo lo imaginario a partir de los hechos acaecidos en su propia historia. A la vez, menciono los elementos literarios que ayudan a fortalecer esa necesidad de almacenar y proteger herramientas privilegiadas para la sociedad chilena. Las partes que se desarrollarán aquí son las siguientes: la función de la escritura en la historia, las diferencias y las semejanzas entre novela e historia, la novela histórica y lo imaginario en la memoria colectiva. 
La escritura es un modo de conciliación del hombre con su pasado y su presente, su condición y su marginalización a la que estuvo secularmente sometido, tanto por su género como por su clase. De esta manera, los efectos que ocasiona sirven como antídoto a esa realidad, con la incorporación de referentes embellecidos o la argumentación que menciona Paul Ricoeur: "Toda la historia del sufrimiento clama venganza y pide narración" (145). A través de la escritura, también, se consigue el conocimiento. Este será útil para superar todo tipo de dificultades y convivir según las exigencias de la praxis. Peter Burke articulaba que la lengua representa a la sociedad. Es decir, muestra el bagaje lingüístico (la entonación, el léxico, las voces o la morfosintaxis) y las variaciones ideológicas (de una nación, una región o cualquier tipo de colectividad) que determinan a una cultura o una identidad (34).

María Gómez Martín asume que todo tipo de trama ficcional, que intenta demostrar algo autobiográfico, emplea como recurso la narración en primera persona (137). Eso permitirá una adecuada introspección psicológica. Si se pretende transmitir la historia con otro fin (el subjetivo), pues habrá más atención a la vida interior que a los acontecimientos públicos. Verbigracia, en el siguiente pasaje de la novela de García Márquez, se toma un criterio personal sobre algunos cambios apreciados luego de la dictadura de Pinochet:

Pero también los militares estaban bien preparados. Nos contaban con mucha seguridad el significado y la historia de cada estancia del palacio, y la forma en que fue restaurado en relación con el edificio anterior, pero hacían prodigios de evasivas y circunloquios para no referirse al 11 de setiembre de 1973. La verdad es que la restauración se hizo con una gran fidelidad a los planos originales. Tapiaron unas puertas, abrieron otras, derribaron muros, cambiaron tabiques de lugar, y eliminaron la entrada de Morandé 80, por donde los presidentes recibían las visitas privadas. Fueron tantos los cambios, que alguien que hubiera conocido el palacio antiguo no sabría orientarse en el nuevo (88).

Tanto la novela como la historia, plasman sus características inmanentes, aunque tienen también elementos en común. Estos facilitan una comunicación directa con la realidad. La novela es la obra literaria en la que se narra una o varias acciones aparentes, que, a su vez, conlleva un efecto de recepción estético agradable para el lector, ya que en estas ficciones se muestra el pasado de manera crítica y veraz. Es más, es posible la incorporación de otras 
versiones más enriquecedoras, como proporcionarles voz a los vencidos y los marginados. María Fernández García indica que la finalidad de esta creación es la de cuestionar el proceso complejo de la memoria colectiva (172).

La historia abarca la narración y la exposición verdadera de los acontecimientos pasados y lo memorable - Marguerat y Bourquin planteaban que la estructura de la historia no es más que su trauma - El historiador tiene aquí la posibilidad de reparar, "rehablar" al texto y regenerarlo, según Albert D' Haenens (21). En esta, no se aprecia una versión distinta de la de los documentos o los monumentos. Por ese motivo, los olvidados o los marginados no tienen VOZ.

Ambas (novela e historia) contribuyen a la construcción de un imaginario sobre una determinada época o figura histórica, ya sea con intereses invariables o modelos psicológicos y culturales, sin apartar en estas la verosimilitud. Epistemológicamente, hay un reconocimiento de la naturaleza discursiva del pasado, como un saber, con el empleo del material histórico, para narrarlo diferente, con un propósito diferenciado. En consecuencia, se alcanza una conciencia histórica.

Para Carlos García Gual, la novela histórica es un género de vocación popular identificable, que combina la crónica histórica y la ficción novelesca $(11,25)$. Para que su fin sea posible, el novelista debe contar con una buena manipulación de la historia, que se logra mediante la documentación. Si fracasara, no podría facilitar el acceso a los lectores al campo histórico que están deseosos de conocer. Además, se recurrirían a anacronismos, como incompatibilidad con la época: vestidos, monedas, situación sociocultural, léxico, etc. Al reconstruir los hechos, ofrece ese respaldo de la novela, como si se tratase de una reunión orgánica del pasado o una racionalidad de la historia (una conciencia nacional), la verdad que constituirá la razón de ser de la novela histórica, según Noé Jitrik (11).

También, el autor puede establecer relaciones con el presente, ya sea de temática política, religiosa, cultural, económica, etc. Es más, en términos de Carmen Díaz de Alda Heikkilä, es capaz de desplazarse a través de los siglos. Eso permite que la novela se base en connotaciones, mensajes y resonancias totalmente inusitadas, que atribuyen una dimensión insospechada (75). Esto sucede en La aventura de Miguel Littín clandestino en Chile (1986), en la cual las alusiones temporales varían según el gusto del autor: narrará hechos acaecidos de la dictadura, hará memoria de ello al realizar el reportaje tiempo después o partirá desde su 
propio presente en el que la dictadura ya concluyó. De esta manera, se infiere que, dependiendo de la importancia de los asuntos históricos y las pretensiones literarias, la obra se adscribirá a algún subgénero o pertenecerá a la categoría de las memorias, los diarios, las biografías, las crónicas, las leyendas, las novelas costumbristas, etc.

Para Juan Escobar, el estado de la cuestión de lo imaginario es multidisciplinario (ilimitado en su representación), aunque se enfoca más en las Ciencias Sociales. Este es un motivo por el cual se justifica la Historia (27). Hay un conflicto medular contra lo real para constituir un espacio de interés, y convertirse en un campo de investigación. En rigor, busca construir la realidad de lo imaginario. Por lo tanto, referirse a la historia de lo imaginario es evocar a la historia de los arquetipos, como al recordar hechos pasados, cuentos, narraciones y manifestaciones orales. A todo ello, Juan Escobar lo considera como "memoria colectiva" (119). En consecuencia, hasta el momento, Chile ha ido conservando en la memoria unos emblemas que los identifica. Algunos de ellos, más evidentes, son los que se resaltan en la novela, como la figura de la democracia y el representante de la literatura, el Premio Nobel Pablo Neruda. Sobre el primero, textualmente enuncia lo siguiente: "Se conserva viva la memoria de Salvador Allende" (50). Sobre el segundo, se le alude como figura emblemática, la cual es exaltada también. Este modo de aprecio en la historia chilena es debido a que estos cánones tienen mucha influencia sobre la colectividad y, de alguna forma, deconstruyen el silencio y la ignorancia — tal como constata LeAnn Chapleau (80) - para buscar con constancia la justicia nacional. En la historia de Chile, en el periodo de la dictadura de Augusto Pinochet, tanto como en la misma historia y la novela de García Márquez, existe un compromiso social por la paz y la unidad, forjado desde el Gobierno de Allende por el propio sentido nacional.

Esta manifestación de lo imaginario es más evidente en el género mismo de la novela de García Márquez, la cual adopta un matiz de reportaje (o periodismo), en la que recopila hechos verídicos y memorables de la memoria colectiva de Chile. Una crítica sobre este autor, Edila Paz Goldberg, mencionaba que esta forma de trabajar la novela revelaría la conciencia crítica, de modo distinto, al emplear el autor ideologías que denuncian los abusos, las intervenciones violentas del país durante la dictadura chilena y la resistencia política establecida allí (287). Ahora, si existiera una pretensión de asumir la crítica de los abusos del Gobierno de Chile como trayectoria histórica, bastaría con analizar el Gobierno que continuó después: el de Ricardo Lagos, quien tuvo una buena y próspera intención en la presidencia con propuestas de reformas 
constitucionales (Chapleau 80). Sin embargo, para lograrlo, tuvo que luchar con el legado de Pinochet: acción que le fue muy difícil conseguir por las huellas humillantes en la memoria colectiva sobre el presidente anterior.

\section{El golpe de Estado del 11 de septiembre de 1973}

En esta segunda parte, mencionaré las causas del golpe de Estado en septiembre de 1973, realizado en Chile y dirigido por Augusto Pinochet. Asimismo, narraré los sucesos sintéticamente sobre este hecho histórico. Cabe aclarar que en la tercera sección de este artículo se explicarán también algunos detalles de estas manifestaciones violentas, pertenecientes a este acontecimiento subversivo, como también a otras representaciones inhumanas y algunos atentados. Para que sea posible este desarrollo, he confrontado con la novela de García Márquez, merced a que cumple con el estereotipo de una novela histórica.

José Lozano Fuentes y Amalia López Reyes consideran que una de las causas principales del derrocamiento del expresidente Salvador Allende se originó por su pensamiento socialista y comunista, por querer aplicar una política exterior unificadora (América Latina) en contra del imperialismo económico, y, con ello, la imposición del socialismo marxista (395). Otros de los motivos, sin dejar de ser importantes, fueron el hecho de subestimar la capacidad de los conspiradores nacionales e internacionales y el confiar en la tradición chilena de la paz y la legalidad (Chapleau 52). En la novela de García Márquez, se alude a ese motivo de la siguiente forma:

Chile no sólo fue un país modesto hasta el gobierno de Allende, sino que su propia burguesía conservadora se preciaba de la austeridad como una virtud nacional. Lo que hizo la Junta Militar para dar una apariencia impresionante de prosperidad inmediata, fue desnacionalizar todo lo que Allende había nacionalizado, y venderle el país al capital privado y a las corporaciones trasnacionales. El resultado fue una explosión de artículos de lujo, deslumbrantes e inútiles, y de obras públicas ornamentales que fomentaban la ilusión de una bonanza espectacular (38).

En suma, el error de Allende fue querer ejercer un Gobierno reformista, en tanto estructuras sociales y económicas. Esta crisis creciente llevó a la ruptura del sistema político en septiembre de 1973 y la toma del poder por las Fuerzas Armadas, comandada por Augusto 
Pinochet. Así, una conspiración económica neoliberal fue impuesta en el país: asimismo, como consecuencia, eso exigía una reorganización drástica.

Hacen alusión José Lozano Fuentes y Amalia López Reyes de que el 11 de septiembre de 1973 las FF. AA. de Chile y la guardia de los carabineros derrocaron el régimen y el Gobierno democrático de Allende (395). Eso generaría el fin del socialismo y la democracia, y se instauraría una dictadura. A partir de ese instante, empieza una cruel campaña de abolición, a cargo de grupos fascistas de asesinos en uniformes, que provenían de Estados Unidos, a expensas de liquidar a democráticos y libertarios; entre ellos, obreros, campesinos, partidarios de la Unidad Popular, cristianos de la izquierda, defensores de lo espiritual y la cultura, profesores, médicos, estudiantes, mujeres y niños.

\section{La dictadura y lo delictivo como violación a los derechos humanos}

En esta tercera sección, analizo los mecanismos que permitieron que la dictadura tomara un fin macabro al violar los derechos humanos, al igual que las secciones anteriores, confronto con ejemplos de la novela de García Márquez. Los subtemas que desarrollo son la dictadura, la democracia mal constituida, la violación a los derechos humanos, la función criminal que cumplió la Dirección de Inteligencia Nacional (Dina), la falta de comunicación, el rol de los opositores y los demócratas y, para finalizar, algunos cambios en la vida chilena luego de la dictadura de Pinochet.

La imagen del dictador aparece ya desde el siglo XIX. Esta se caracteriza por establecer un hito en la materia literaria, ya que se la observa como una entidad antagonista o una enemiga social o interior que, en términos de Danny Monsálvez Araneda, se distancia de todo orden instaurado en la sociedad, y sirve como lección para que la ley penal proteja los abusos desmedidos posteriormente (defensa del orden) (7). Al ser una amenaza para la seguridad propia o ser diferente, ya es caótico. Una dictadura implica legitimar popularmente, con el posicionamiento del orden. A su vez, se restablecen límites específicos y fijos para la construcción natural de una jerarquía social. De la misma manera, Monsálvez Araneda sostiene que el resultado de esta proyección social y política es una sociedad vigilada, finalmente encarcelada (17). En la dictadura de Augusto Pinochet, estos elementos se originaron sobre la base del incentivo primordial. Esas fuerzas reaccionarias, el capitalismo cimentado y los intereses extranjeros. Con ello, se configuró un Estado terrorista, el cual portaba con la 
necesidad de adaptar una determinada legalidad y una nueva institucionalidad. Todo eso era producto de una lucha total y permanente. En ese periodo, se privilegian los castigos, y se afirma con ello el orden con la presencia del terror. Verbigracia, cerciórese la tensión suscitada en una dictadura, en la novela de García Márquez, cuando se trata de confrontar con el equipo militante:

El edificio de Chile Films estaba rodeado de soldados con ametralladoras emplazadas en trípodes, y apuntando hacia la entrada principal. El portero de boina negra, con la insignia del Partido Socialista, salió a nuestro encuentro.

—Ah — gritó señalándome—, ese caballero, el señor Littín, es el responsable de todo lo que ocurre aquí.

El sargento le dio un empujón que lo tiró por tierra.

—Váyase a la mierda —le gritó—. No sea maricón (21).

Se intuía una guerra psicológica y moral (interna) en la dictadura de Pinochet, merced a que el marxismo internacional, detectado por el pensamiento militar, arriesgaba la seguridad del Estado con ataques subversivos. Por lo tanto, las Fuerzas Armadas se autoconfiguraban salvaguardia de la nación. Eso significaba aceptar sus expresiones violentas, en las que se ponían en riesgo los valores, la unidad nacional y la uniformidad de la sociedad (Monsálvez 12). Debían exterminar el extremismo y hallar el centro de operaciones de los marxistas. Puesto que se proclamaba una nacionalidad, la guerra era permanente entre el Occidente cristiano y el Oriente comunista. Ese ideal ya pervivía entre militares y civiles. Por ello, ya se auscultaban las acciones que tomaría cada uno. En la novela de García Márquez, las impresiones generadas en el espectador están impregnadas de terror:

De golpe, en una curva, nos encontramos de frente con varias camionetas de la CNI que formaban una especie de túnel a los dos lados del camino. Los agentes de civil estaban armados con metralletas. Eloísa trató de frenar, pero yo se lo impedí (69).

Danny Monsálvez encuentra en el proceso de represión, la dictadura cívico-militar de Augusto Pinochet (1973-1989), dos aspectos de carácter internacional o latinoamericano: primero, las Dictaduras de Seguridad Nacional y, segundo, la Operación Cóndor (estructura y 
coordinación represiva, a nivel regional, que se encargaba de hacer desaparecer a los llamados opositores o enemigos de los respectivos regímenes militares del Cono Sur) (1).

Esta operación surgió en distintos países de América Latina. En ellos, se vivieron intensos problemas con los que respecta a una democracia anómala. Luego, en el siglo XIX, se notó la presencia de caudillos que se sublevaban al Gobierno para controlar políticamente sus respectivos países. En el siglo XX, este asunto se complica más, ya que el motor principal será la motivación personal de cada caudillo para efectuar su respectivo levantamiento. Una de las excusas primordiales, en el caso de Chile, era la de percibir el país como un enfermo al que debía sanarse (un proceso a largo plazo que tan solo se llevaría a cabo con un régimen cívicomilitar). Una vez logrado ese fin, se obtendría la aniquilación del marxismo y la politiquería, para que surgiera una democracia que estaría aún bajo la vigilancia militar.

Luego del bombardeo de La Moneda y la inmolación del presidente Salvador Allende, el 11 de septiembre de 1973, tomaron como prisioneros a quienes lucharon por la democracia y el socialismo en pluralidad y libertad. Más adelante, en 1980, el general Augusto Pinochet interviene de forma efectiva para difundir la democracia. Para ello, realiza un plebiscito (Constitución), que resulta parcialmente democrático, debido a que las redes políticas no dejan de ser dictatoriales (lo militar administra lo ejecutivo y el Congreso, gracias al Consejo de Seguridad Nacional), y Chile sigue siendo gobernado por ese Estado en peligro de disturbios. Este régimen significa que no hay una protección constitucional normal a las libertades civiles. En la novela de García Márquez, ese tránsito hacia la democracia se instaura desde que Pinochet toma la dictadura:

Al principio de su gobierno, el general Pinochet proclamó su voluntad de permanecer en el poder hasta borrar en la memoria de las nuevas generaciones el último vestigio del sistema democrático. Lo que nunca se imaginó fue que su propio régimen iba a ser la víctima de ese propósito de exterminio. Hace poco, desesperado por la agresividad de los muchachos que se enfrentan a piedras en la calle contra las fuerzas de choque, que combaten con las armas en la clandestinidad, que conspiran y hacen política para restablecer un sistema que muchos de ellos no conocieron, el general Pinochet gritó fuera de sí que esa juventud hace lo que hace porque no tiene la menor idea de lo que era la democracia en Chile (50-51). 
Chile vivió un estado de tensión al someterse a las nuevas reglas del Gobierno dictatorial de Augusto Pinochet. Gabriel García Márquez representa con veracidad ese motivo, con la intención de otorgar a la narración esa sensación de realismo, tal como se observa en el siguiente fragmento:

Doce años antes, a las siete de la mañana, un sargento del ejército al frente de una patrulla había soltado sobre mi cabeza una ráfaga de ametralladora, y me ordenó incorporarme al grupo de prisioneros que iban arreando hacia el edificio de Chile Films, donde yo trabajaba. La ciudad entera se estremecía con las cargas de dinamita, los disparos de armas largas, los vuelos rasantes de los aviones de guerra. El sargento que me había detenido andaba tan ofuscado, que me preguntó qué estaba pasando. "Nosotros somos neutrales", decía. Pero no supe por qué lo decía ni a quiénes incluía en el plural. En un momento en que nos quedamos solos, me preguntó:

_ ¿Usted es el que hizo "El Chacal de Nahualtoro"?

Le contesté que sí, y pareció olvidarse de todo, de los tiros, de las cargas de dinamita, de las bombas incendiarias en el palacio de los presidentes, y me pidió que le explicara cómo se hace para que a los falsos muertos de las películas les salga sangre por las heridas. Se lo expliqué y pareció fascinado. Pero casi en seguida volvió a la realidad.

—No miren para atrás — nos gritó— porque les vuelo la cabeza (20).

Muchos estuvieron amenazados o desaparecidos. Otros fueron asesinados, torturados o exiliados, mientras que otro grupo tan solo se dedicaba a acatar las reglas sumisamente. Este tipo de violaciones a los derechos humanos provocó una alteración a la convivencia pacífica en el interior del Estado, como ocasionaría en cualquier territorio emergente. Una de las razones por la cual se llegaron a emplear estas medidas fue por la perspectiva política que se tuvo en ese Gobierno: hubo una incapacidad política para asimilar las bases legítimas de un Estado que estuvieran desligadas de la democracia. Otra cita del texto de García Márquez revela esta condición inhumana, atacada por la participación militante de Pinochet.

A partir de la usurpación violenta del poder y el derrocamiento del gobierno constitucional de Salvador Allende, el régimen de Pinochet apoyado por las Fuerzas Armadas, se caracterizó por su afán desmovilizador, su represión exacerbada y clandestina 
de manera muy violenta en contra de la disidencia política; es decir la violación sistemática del Estado de derecho; así como también de los derechos humanos.

A fines de febrero de 1985, en efecto, tres militantes de la oposición fueron secuestrados con un alarde de fuerza que no permitía poner en duda quiénes eran los autores (24-25).

LeAnn Chapleau menciona que en octubre de 1973 se asesinaron a algunos presos de las cárceles (54). La brutalidad militar era irrefrenable: seguían muchos años de represión, tortura, exilio y barbarie. La mayoría de la gente era buscada en las calles para ser detenida. Quienes se resistieran se acercaban a un peligro mayor: torturas y asesinatos. Por ejemplo, María Eugenia Horvitz vio un caso de tortura de un tal Enrique, quien fue quemado con soplete, baleado y tirado al Mapocho. Según el Informe Rettig, los detenidos de Villa Grimaldi sufrieron torturas más atroces: les pasaban electricidad en la "parrilla", mientras este presenciaba la tortura de alguno de sus parientes, con la finalidad de que él informara todo lo solicitado y lo necesario para los militares —el hijo del secretario general del Partido Comunista también fue torturado con el mismo procedimiento-. A los torturados, se les exigía mantener una postura de suplicio antes de morir, según fue declarado ante la Comisión Internacional Investigadora de los Crímenes de la Junta Militar en Chile, en febrero de 1975 (México). Durante el proceso del plebiscito (1987-1988), también, se vieron diversas violaciones a los derechos humanos, con la justificación inminente de las elecciones.

Además, existe un ambiente de inseguridad y traición entre compatriotas. La confianza se ha perdido, y no hay muestras de seguridad nacional, tal como lo muestra la novela en el siguiente fragmento: "No sé por qué me pareció que era el Guatón Romo, un sicario de la dictadura que se había hecho pasar por un izquierdista ardoroso, y denunció a numerosos activistas clandestinos que luego fueron sacrificados" (64).

Augusto Pinochet fue el jefe máximo de la Dirección de Inteligencia Nacional (Dina): conoció y aprobó todos los crímenes de sus subordinados. A la vez, este comportamiento provocó la consolidación del presidente como dictador (diciembre de 1974). Según Mario Amorós, desde principios de 1974 hasta su transformación en la Central Nacional de Informaciones (CNI) en agosto de 1977, la Dina fue la primera responsable de la política de abolición contra el movimiento popular, decretada por la junta militar y el general Augusto Pinochet $(1-2)$. 
Por otra parte, la Dina tuvo las siguientes funciones:

- Tomando en cuenta la existencia de la Cooperación con países sudamericanos, la Dina reprimía a los subversivos: los detenían y los desplazaban a los campos de concentración que había en Chile (Villa Grimaldi, Tejas Verdes, Colonia Dignidad, etc.).

- Tuvo funciones de inteligencia y seguridad en Chile y el exterior. Por otro lado, reunía información, la analizaba y proponía políticas de Gobierno, según convenía al caso (ya sea de carácter público, nacional o extranjero).

- Desarrolló tareas y programas de apoyo: control de registros públicos, establecimiento de colaboradores e informantes para dichas funciones, supervisión de los beneficios estatales de los nombramientos, instauración de relaciones internacionales de coordinación con otros servicios de inteligencia, y distintos quehaceres para obtener fondos con personas naturales o empresas (Amorós 11).

Ante ello, se busca refundar Chile con proyectos ilusorios y poco creíbles, ya que la acción de la Dina revelaba cierto matiz terrorista en el Gobierno de Pinochet. Verbigracia, en el campo político, se buscó la instauración de una democracia protegida. En la parte económica, la necesidad de imponer un programa neoliberal. Los métodos que aplicaron los agentes de la Dina fueron diversos (Amorós 13). Para que su realización fuera posible, contaban con maquinarias y conocimientos concretos en función de la aplicación de las sesiones de torturas. Algunos de los métodos usados fueron los siguientes:

- El colgamiento de la víctima en una barra por las muñecas y las rodillas, durante mucho tiempo. A ello, se le añadían descargas de corriente eléctrica, más golpes, heridas cortantes u otras afrentas.

- La asfixia, como el hundimiento de la cabeza de la víctima en un recipiente de agua sucia u otro líquido. También, se le colocaba una bolsa de plástico en la sien hasta producirle la muerte.

- El uso de drogas, como las inyecciones de pentotal sódico, que hacía que el detenido estuviera casi apto para emitir declaraciones importantes.

- La realización de torturas, con el empleo de golpes físicos brutales. 
Algunos casos en los que la Dina participa como torturadora los menciona Danny Monsálvez, quien acata la ejecución y la desaparición de muchos resistentes (16) —en 1997. se registró un total de 600000 y 800000 personas víctimas de la tortura durante la dictadura de Pinochet-. Se tomaba como creencia de que quien participaba de movimientos opositores tenía con sí toda una familia y amigos que apoyaban su línea política, motivo por el cual los aparatos represivos de la dictadura (Dina y CNI) saqueaban a cuantos podían. Entre 1974 y 1977, muchos militantes y dirigentes del Partido Comunista, el Partido Socialista, el MIR, entre otros, fueron secuestrados, torturados o asesinados en los centros de detención clandestina de la Dina. Por ejemplo, los esposos Sergio Pérez y Lumi Videla, dirigentes del MIR, fueron asesinados en 1974.

LeAnn Chapleau informa que distintos medios de comunicación fueron vetados por el peligro y la amenaza que significaban al régimen del general Augusto Pinochet (63-64) —este “apagón cultural” continuó por 17 años-. Algunas de estas manifestaciones eran la música, la poesía, el teatro, las revistas, entre otras formas de expresión libre; mientras que, en el Gobierno de Allende, estos métodos poderosos de comunicación sí fueron permitidos. En La aventura de Miguel Littín clandestino en Chile (1986), predominan alusiones heterogéneas a esta modalidad, como el siguiente monólogo:

Caminé por la calle Estado, por la calle Huérfanos, por todo un sector cerrado al tránsito de vehículos para solaz de los peatones, como la calle Florida de Buenos Aires, la Vía Condotti de Roma, la Plaza de Beaubourg de París, la Zona Rosa de la Ciudad de México. Era otra buena creación de la dictadura, pero a pesar de los escaños para sentarse a conversar, a pesar de la alegría de las luces, de los canteros de flores bien cuidados, aquí se transparentaba la realidad. Los pocos grupos que conversaban en la esquina lo hacían en voz muy baja para no ser escuchados por los tantos oídos dispersos de la tiranía, y había vendedores de cuantas baratijas se podían concebir, y muchos niños pidiendo dinero a los peatones. Sin embargo, lo que más me llamó la atención fueron los predicadores evangélicos tratando de vender la fórmula de la dicha eterna a quien quisiera oírlos (16).

Luego del 11 de septiembre, se incentiva un absoluto desprecio por la dignidad de millones de seres humanos y la vulneración de todas las libertades democráticas (Amorós 5). 
Conllevó una refundación del país en términos políticos, culturales, económicos, sociales y psicológicos. Algunas medidas de resistencia y oposición son específicas en la novela analizada. Verbigracia, cerciórense los siguientes casos:

- "También desde allí se denuncian las torturas y se fomentan campañas por los desaparecidos y por toda clase de injusticias" (24).

- "Toda una generación se cortó el cabello antes de que las patrullas militares se lo cortaran con bayonetas, como tantas veces lo hicieron en los primeros días del golpe de cuartel" (39).

- ' “La marcha del hambre' había sido reprimida con una brutalidad sangrienta, y la policía había golpeado a algunos miembros de nuestros equipos y destrozado una cámara" $(85-86)$.

Un modo de detener las diversas manifestaciones de opositores era haciendo recordar lo acaecido el 11 de septiembre de 1973, indicación que remarca también el texto de García Márquez. Esta medida se trataba de una forma de condicionar la tranquilidad con una propagación de terror:

Las fuerzas de oposición, legales e ilegales, a las cuales se sumaban por primera vez los sectores más progresistas de la burguesía, convocaron un paro nacional de un día. Fue una demostración de poderío y determinación sociales que exasperó a la dictadura y precipitó el estado de sitio. Pinochet, desesperado, lanzó un grito que resonó en el mundo con acordes de ópera:

— Si esto sigue así tendremos que hacer un nuevo once de septiembre (9).

Según LeAnn Chapleau, las múltiples expresiones de resistencia durante la dictadura de Pinochet no son más que plasmaciones de cómo son la vida y el pensamiento de los chilenos (47). De allí, se extraen otras variedades de expresión, como la literatura y el arte, y relacionarlas con la política. Por ejemplo, en la novela, se detecta una mera representación correlativa con esa realidad, de la que se demarcan las posibilidades de acción de los civiles (entre la libertad y la acechanza militar): 
Más tarde descubrí que la escasez de fuerza pública en las calles era una pura ilusión para recién llegados. A toda hora hay patrullas de choque escondidas en las estaciones principales del tren subterráneo, y camiones provistos de mangueras de agua a alta presión en las calles laterales, listos para reprimir con una saña brutal cualquier brote de protesta de los tantos intempestivos que ocurren a diario. La vigilancia es más intensa en la Plaza de Armas, centro neurálgico de Santiago, donde está la sede de la Vicaría de la Solidaridad, que es un gran bastión contra la dictadura auspiciado por el cardenal Silva Henríquez y con el apoyo no sólo de los católicos sino de todos los que luchan por el retorno de la democracia en Chile (24).

La mayoría de la gente se opuso al Gobierno. Por lo tanto, gran parte fue condenada al exilio, mientras que otros se quedaron en Chile, pero con cierto resentimiento, con su propia cultura, sus vidas en riesgo, puesto que, tarde o temprano, resultaban revelando la verdad escondida. La violencia física se ejercía como medio para hallar esa respuesta, por parte de los militares a los activistas. En algunos casos, las oposiciones se hacían de manera llamativa, tal como las señala la novela de García Márquez:

Sebastián Acevedo no hizo una súplica sino una advertencia. Como el arzobispo estaba de viaje, habló con los funcionarios del arzobispado, habló con los periodistas de mayor audiencia, habló con los líderes de los partidos políticos, habló con dirigentes de la industria y el comercio, habló con todo el que quiso oírlo, inclusive con funcionarios del gobierno, y a todos les dijo lo mismo: "Si no hacen algo por impedir que sigan torturando a mis hijos, me empaparé de gasolina y me prenderé fuego en el atrio de la Catedral" (4243).

En febrero de 1988, los partidos políticos chilenos opositores (Concertación de Partidos por el NO) rechazaron la permanencia de Pinochet en el poder. Los resultados fueron beneficiosos para ellos en el plebiscito del 5 de octubre 1988 con el $54 \%$ de los votos (Chapleau 72). Esto permitió que se desarrolle una coalición electoral por las votaciones de diciembre 1989, de las que Patricio Aylwin ganó con su Partido Demócrata Cristiano (aunque Pinochet constitucionalmente sería el comandante jefe por diez años más). 
A pesar de haber pasado por una dictadura en la que hubo diversos atentados contra los derechos humanos, se mantuvo ese espíritu vivo de la nación por seguir luchando, tal como lo señaló Luis Alberto Corvalán en la Comisión Internacional. La novela de García Márquez hace preeminencia en corroborar cómo fue mejorando el sector económico: "La deuda externa de Chile, que en el último año de Allende era de cuatro mil millones de dólares, ahora es de casi veintitrés mil millones" (38). También, alude a la memoria colectiva que aún mantiene esa sagacidad por la lucha y la resistencia política, a expensas de defender esa nación, sin importar que sea a través de un discurso escrito: "De pronto, alguien pasó cantando la célebre canción de Pablo Milanés: 'Yo pisaré las calles nuevamente de lo que fue Santiago ensangrentada'" $(17)$.

\section{El exilio en Chile}

En la historia de América Latina, se nota el desarrollo del exilio en Gobiernos dictatoriales, como el de Chile. Esta modalidad de imponer control se percibe a inicios de la dictadura cívico-militar de Augusto Pinochet. Este dispositivo empleado en el Gobierno represivo no solo tenía como objetivo expulsar del territorio a determinadas personas, merced a que su verdadera intención era demarcar social y políticamente a ese enemigo (interno), que era "foco" de peligrosidad. Según Danny Monsálvez, del mismo modo, se trataba de ejercer una disciplina social de la población y configurar un Estado de Seguridad Nacional, ya sea por la represión o la persuasión (3). En el país, no se aceptó ni una forma de expresión violenta: si no eran sometidos al rigor de la justicia militar, eran exiliados (Monsálvez 12). Estos no podían destruir o alterar por actos bélicos el orden establecido en los sistemas de Gobierno; tampoco, de que difundieran doctrinas que atentaran contra la soberanía nacional, la seguridad interior, el orden público y el Estado. Eran considerados, también, por estas causas, como agitadores o activistas. Es lo que señala Danny Monsálvez Araneda (14). El protagonista de la novela de García Márquez tiene todas estas características, junto con otros personajes de quienes se hacen descripciones, como el caso de Elena:

Era Elena, una militante de la resistencia chilena, joven y muy atractiva, designada por su organización para mantener las comunicaciones con la red clandestina interior, establecer los contactos secretos, determinar los lugares apropiados para los encuentros, valorar la situación operativa, concertar las citas, velar por nuestra seguridad (3). 
El hecho de que diversos resistentes fueran condenados al exilio exigió que ellos adoptaran medidas de escape, como la de optar por la clandestinidad. Es lo que caracteriza la novela La aventura de Miguel Littín clandestino en Chile (1986), desde la vida misma del protagonista, hasta la finalidad que tiene de residir en su nación: filmar un documental de su país luego de la dictadura de Pinochet. A continuación, citaré cuatro casos evidentes, narrados desde la primera persona, en los que se hace alusión a esta nueva modalidad de vida, al haber sido Miguel Littín uno de los personajes condenado al exilio y conducido a la clandestinidad:

- "Yo, Miguel Littín, hijo de Hernán y Cristina, director de cine y uno de los cinco mil chilenos con prohibición absoluta de regresar, estaba de nuevo en mi país después de doce años de exilio, aunque todavía exiliado dentro de mí mismo: llevaba una identidad falsa, un pasaporte falso, y hasta una esposa falsa. Mi cara y mi apariencia estaban tan cambiadas por la ropa y el maquillaje, que ni mi propia madre había de reconocerme a plena luz unos días después" (3).

- "Este sueño se hizo más apremiante cuando el gobierno chileno empezó a publicar listas de exiliados a los que se les permitía volver, y no encontré mi nombre en ninguna. Más tarde alcanzó extremos de desesperación cuando se publicó la lista de los cinco mil que no podían regresar, y yo era uno de ellos" (4).

- "En realidad, el proceso más difícil para mí fue el de convertirme en otra persona. El cambio de personalidad es una lucha cotidiana en la que uno se rebela a menudo contra su propia determinación de cambiar, y quiere seguir siendo uno mismo. Así que la dificultad mayor no fue el aprendizaje, como pudiera pensarse, sino mi resistencia inconsciente tanto a los cambios físicos como a los cambios del comportamiento. Tenía que resignarme a dejar de ser el hombre que había sido siempre, y convertirme en otro muy distinto, insospechable para la misma policía represiva que me había forzado a abandonar mi país, e irreconocible aún para mis propios amigos" (5-6).

- "Este era en realidad un auténtico pasaporte uruguayo, con el nombre y todas las señas de su titular legítimo, el cual nos lo había dado como una contribución política, a sabiendas de que iba a ser manipulado y utilizado para entrar en Chile" (10). 
Los exiliados no tenían derecho al Derecho. Para adoptar las medidas del caso, era indispensable registrar la documentación de los ciudadanos, a expensas de percatarse de quiénes eran los que podían vivir en ese territorio. Los mecanismos de prevención asumidos fueron demasiado estrictos. Es más, la Junta publicó un Decreto Ley $n .^{\circ} 81$, en el que se sancionaba, también, a las personas que desobedecieran las amonestaciones que imponía el Gobierno. Tomando como referencia la seguridad del Estado, se condenaba a presidio, se prohibía el retorno de los chilenos sancionados que estaban en el extranjero; caso contrario, si les dispensaban la falta deberían contar con una autorización del Ministerio de Interior. Monsálvez Araneda se refería a este documento, en relación con los clandestinos y quienes colaboraran a escapar a los exiliados, a que ellos, si se obviaban las manifestaciones de control y atentar contra la seguridad del Estado, serían sometidos a tribunales mayores, de donde se podrían designar penas mayores, como la muerte (13).

\section{Conclusiones}

A continuación, plasmaré las deducciones inferidas de las cuatro secciones de este artículo. Primero, la novela histórica, en el caso propuesto por Gabriel García Márquez, consigue la identificación con sucesos coetáneos en su representación temporal para lograr la construcción trascendental de lo imaginario. Este persiste como una huella inquebrantable de la memoria cultural y colectiva. Segundo, el golpe de Estado del 11 de septiembre de 1973 cuestiona los mecanismos que se autodenominan democráticos. A su vez, se indaga sobre la forma prudente de actuar de sus respectivos gobernantes, sin que exista un mayor número de afectados. Tercero, la dictadura y lo delictivo son asumidos de manera negativa, por el hecho de transgredir los derechos humanos. La Dina, la CNI, las Fuerzas Armadas y otros organismos que buscan la protección de la sociedad chilena facilitan la exposición de una dinámica coherente que establece una regulación en ese periodo dictatorial y la eclosión de diversas modalidades anticriminales. Cuarto, el exilio en Chile en la etapa incorporada de la novela permite destacar la inmoralidad que se atraviesa durante una dictadura. Asimismo, es un espacio para erigir e investigar nociones en función de la ayuda ciudadana, como el hecho de especializarse en el conocimiento de sus propios derechos. 


\section{Referencias}

Amorós, Mario. "La Dina: el puño de Pinochet". Actas del 53. ${ }^{\text {er }}$ Congreso Internacional de Americanistas. Ciudad de México, Jul. 2009, 1-25. Web. 19 Jun 2020.

Burke, Peter. Hablar y callar: Funciones sociales del lenguaje a través de la historia. Barcelona: Gedisa Editorial, 1996. Impreso.

Chapleau, LeAnn. "La cultura chilena bajo Augusto Pinochet". Chrestomathy: Annual Review of Undergraduate Research at the College of Charleston 2 (2003): 45-83. Impreso.

Díaz, Carmen. "La novela histórica como máscara: análisis de la novelística José Luis Sampedro". Actas del XII Congreso de la Asociación Internacional de Hispanistas. Ed. Trevor J. Dadson. 1995. 72-83. Centro Virtual Cervantes. Web. 15 Jun. 2020.

Escobar, Juan. Lo imaginario: Entre las ciencias sociales y la historia. Medellín: Cielos de Arena, 2000. Impreso.

Fernández García, María. "Dictadores de novela: Franco y Salazar en la narrativa contemporánea española y portuguesa". Limite, (2), (2008): 159-186. Impreso.

García Gual, Carlos. Apología de la novela histórica y otros ensayos. Barcelona: Península, 2002. Impreso.

García Márquez, Gabriel. La aventura de Miguel Littín clandestino en Chile. Ciudad de México: Editorial Diana, 1986. Impreso.

Goldberg, Edila. Enfoque analítico de la obra narrativa de Gabriel García Márquez. Aproximación a la ideología de sus textos. Tesis doctoral. Salamanca: Universidad de Salamanca, Facultad de Filología, Lengua Española, 2012. Impreso.

Gómez Martín, María. "Memoria histórica y literatura: la consagración de un pacto". Crisis, dictaduras, democracia: Actas del / Congreso Internacional de Historia de Nuestro Tiempo. Eds. C. Navajas y D. Iturriaga. Logroño: Universidad de La Rioja, 2008. 135146. Impreso.

Haenens, Albert D'. El texto traza de la anterioridad escribal: De lo escrito como documento histórico. Lima: Universidad de Lima, 1993. Impreso.

Jitrik, Noé. Historia e imaginación literaria: Las posibilidades de un género. Buenos Aires: Biblos, 1995. Impreso.

Lozano Fuentes, José y Amalia López Reyes. Historia de América. México: Compañía Editorial Continental, 1995. Impreso. 
Monsálvez Araneda, Danny. "Chile, la dictadura cívico-militar de Augusto Pinochet y el exilio como dispositivo de control social: el caso de la ciudad de Concepción". Actas de la / Jornadas de Trabajo sobre Exilios Políticos del Cono Sur en el siglo XX. La Plata: Universidad Nacional del Sur, 2012. Memoria Académica. Web. 8 Jun. 2020.

Ricoeur, Paul. Tiempo y narración: Configuración del tiempo en el relato histórico. Tomo I. Madrid: Siglo Veintiuno Editores, 1998. Impreso. 